\title{
SRPSKI SREDNJOVEKOVNI MANASTIRI KAO SPONA IZMEĐU VERSKOG I KULTURNOG TURIZMA
}

\author{
Bojan Živadinović1, \\ Miroslav Knežević ${ }^{2}$ \\ 'Student doktorskih studija, \\ Univerzitet Singidunum, \\ Beograd, Srbija \\ 2Univerzitet Singidunum, \\ Beograd, Srbija
}

Correspondence:

Bojan Živadinović

e-mail:

restoranizvor.zivadinovic2@gmail.com

\section{Rezime:}

Brojni su elementi koji povezuju kulturu i turizam. Kultura je prisutna stalno i svuda, a turizam kulturu „traži“ da bi zadovoljio potrebe putnika. Kulturni turizam postaje najbrže rastući segment turističke privrede. Zemlje koje drže do očuvanja kulturnog nasleđa najviše i prihoduju od posetilaca rešenih da to nasleđe što bolje upoznaju. Srbija poseduje kulturno istorijske spomenike i među njima značajan broj srednjovekovnih manastira. Tema ovog rada je moguća valorizacija pravoslavnih svetinja, kao dela kulturnog nasleđa u svrhe razvoja turizma. Nasleđe, koje nam je dinastija Nemanjića i njihovih naslednika ostavila u amanet, osnov je sadašnjeg postojanja verskog turizma u Srbiji i neprocenjivo vredna zaostavština za razvoj budućih turističkih kretanja u okviru ovog vida turizma.

Ključne reči:

kulturni turizam, pravoslavna crkva, kulturno-istorijski spomenici, verski turizam, srpski manastiri

UVOD

Po definiciji, turizam je povezan sa putovanjima i promenom mesta boravka. Najmasovniji vid turizma još uvek se vezuje za sunce i pesak, koji podrazumeva odmor na popularnim destinacijama i plažama poput Španije, Italije i Francuske Grčke, Crne Gore, Hrvatske, kao i drugih razvijenih destinacija. Ove države ubiraju značajna finansijska sredstva od ovog vida turizma. U ukupnim turističkim kretanjima značajno je napomenuti i sve veće učešće planinskog turizma. (Todorović \& Maksimović-Rubežanović, 2014) Međutim, najnovija istraživanja s kraja 20. i početka 21. veka, pokazuju da ovi, dosad najmasovniji, vidovi turizma beleže primetan pad. Taj pad je jednim delom izazvan i porastom interesovanja turista, koji su u potrazi za kulturnim edukovanjem u okviru svog turističkog pohoda na neku destinaciju (Popesku, 2018) Kulturni turizam, iz godine u godinu, beleži sve veći rast. Porast ovog vida turizma je u direktnoj proporciji sa novcem uloženim u očuvanje kulturnoistorijskih spomenika. (Richards, 2018) Shodno tome, bogatije zemlje ostvaruju veće prihode izdvajajući velika sredstva u cilju, pre svega, očuvanja ali u isto vreme i valorizacije svoje kulturne baštine. U vreme kada značajan deo svetskog turizma čine turistička kretanja inspirisana kulturnim dobrima, Srbija bi morala da zauzme svoje mesto na kulturnoj turističkoj mapi, jer bi svakako savremenom turisti imala šta da ponudi. 
Manastiri srpske srednjovekovne države su biseri, koje sa aspekta turizma treba iskoristiti i kao takvi su prepoznati u nacionalnoj strategiji razvoja turizma do 2025. godine. Međutim, odnos crkve prema turizmu i korišćenju manastira u turističke svrhe je svakako nešto drugačiji. Sigurno da postoje određene razlike u pogledu korišćenja manastira Srpske pravoslavne crkve u turističke svrhe i toga kako se prema tom pitanju odnosi sveštenstvo, za razliku od turističkog sektora. Ako za trenutak zanemarimo te razlike, finansijski efekti, takvog oblika turizma, ostvareni posetama manastira od strane turista su pozitivni, ali mogu biti još bolji. Ozbiljnijim pristupom, koji bi sagledao sve pozitivne i negativne strane poseta manastirima u turističke svrhe, mogu se ubirati značajna finansijska sredstva i to je jedan od načina obezbeđenja egzistencije i opstanka ovih svetilišta. Nasuprot tome, ne treba zaboraviti na sakralnost monaštva pravoslavnih svetinja, koja je na tim svetim mestima sačuvana kroz vekove. Taj duhovni deo manastira treba čuvati po svaku cenu, jer je to deo srpske tradicije i kulturno-istorijskog nasleđa. Iz svega navedenog, jasno je da odnosi na relaciji crkva država, sa jedne strane, kao i ekspanzija kulturnog turizama i sakralnosti srpskih pravoslavnih manastira, sa druge strane, nisu dovoljno fokusirani na razvoj ovakvog oblika turizma i nema dovoljno jasno definisanih prioriteta za njegov razvoj. Ovaj rad je koncipiran u cilju prevazilaženja tih različitih gledišta i pronalaženju optimalnog rešenja za sve strane.

\section{KULTURNI TURIZAM I NJEGOVA EKSPANZIJA U SVETU}

Primetno je da kulturni turizam u svetu doživljava pravi bum i u mnogim zemljama u značajnoj meri utiče na povećanje nacionalnog dohotka (Mićunović et al., 2015). Grupa autora, pozivajući se na više izvora, ukazuje da je kulturni turizam usko povezan sa nasleđem graditeljstva i po njihovom mišljenju, kulturni turizam je kretanje ljudi usmereno prema kulturnim spomenicima, koji su van njihovog mesta boravka, u cilju zadovoljenja kulturnih potreba (Podovac et al., 2016). Najpotpuniju definiciju kulturnog turizma daje zaključak sa 22. sednice generalne skupštine UNWTO, održane 2017. godine u Chengduu u Kini, na kojoj je on definisan kao vrsta turističke delatnosti, u kojoj je ključna motivacija posetioca da uči, otkriva, doživi i konzumira opipljive i nematerijalne kulturne atrakcije. (UNWTO, 2017)

Potrebe i zahtevi turističke tražnje stalno se menjaju. Selektivni oblici turizma danas postaju suprotnost masovnom turizmu. „Sunce i more“ više ne zadovoljavaju potrebe savremenog putnika. Savremeni turista želi da mu odmor bude ispunjen i da ga se rado seća, po povratku u stalno mesto boravka (Ivanović \& Rot, 2014). Kulturni spomenici u novostvorenim okolnostima dobijaju veći značaj, a mnoge zemlje kulturu u turizmu, shvataju kao osnovnu vrednost, zbog koje se turizam razvija i od čega zavisi (Milošević, 2013). Kulturne atrakcije obuhvataju skup značajnih materijalnih, ali i duhovnih, emocionalnih i intelektualnih pojava u društvu vezanih za umetnost i arhitekturu, kulturno-istorijsko nasleđe, kulinarstvo, muziku, način života ljudi na određenoj destinaciji, sistemima vrednosti, koji su uspostavljeni, tradicije itd. (Richards, 2018). Zato je značajno naglasiti da kulturni turizam nisu samo kulturno-istorijski spomenici, već su to i kulturne prakse ljudi u svim krajevima sveta (Richards, 2018).

Kulturni turizam danas čini 40\% svih turističkih kretanja (Pivac, 2018.). U mnogim zemljama ovaj vid turizma prepoznat je kao razvojna šansa (Milošević, 2013). Po UNWTO, putovanja osoba iz kulturnih motiva su studijska putovanja, putovanja radi posmatranja umetničkih događaja, kulturne ture, posećivanje mesta i spomenika u cilju proučavanja folklora ili umetnosti i hodočasništvo. (Radović et al., 2017) Kulturni turizam beleži pravi bum u poslednjim godinama dvadesetog i početkom dvadeset prvog veka. Pivac se poziva na statistiku Travel Industry Association (TIA), koja pokazuje rast kulturnog turizma u periodu između 1996. i 2000. godine, koji je u tom periodu dostigao 10\% ukupnih turističkih kretanja , da bi do 2007. godine, ovaj vid turizma narastao na 30\% ukupnih kretanja putnika u turizmu. Danas kulturni turizam čini već pomenutih $40 \%$ svih kretanja u ovoj privrednoj delatnosti u celom svetu, sa tendencijom daljeg rasta. Istraživanja, sprovedena u SAD, pokazuju, da se čak $76 \%$ svih turista zabavljaju kulturnim aktivnostima, što sagledano kroz tu državu, predstavlja brojku od oko 130 miliona turista koji u tu svrhu potroše 171 milijardu dolara godišnje (Chen \& Rahman, 2018). Dalju ekspanziju kulturnog turizma potvrđuju i optimistični izveštaji UNWTO za 2018. godinu. Ovi izveštaji govore u prilog daljeg širenja kulturnog turizma, kao i mogućeg stvaranje novih podvidova kulturnog turizma, sa značajnijim udelom u ukupnim turističkim kretanjima, kao što su turizam kulturnog nasleđa, filmski turizam, književni turizam itd. (Richards, 2018). 
Međutim, da bi se u budućnosti lakše upravljalo kulturnim turizmom od velikog značaja je veština upravljanja kulturnim turistom. Svaki kulturni turista različito doživljava destinaciju kroz četiri dimenzije, a to su: uticaj, očekivanja, posledica i sećanje. Nezaboravna iskustva turiste motivišu da se iznova uključuju u turističke aktivnosti (Chen \& Rahman, 2018). Kulturni turisti posećuju mesta vezana za istoriju naroda, zatim muzeje i takođe uzimaju učešća u različitim manifestacijama i festivalima. Od njih se očekuje da će svoja pozitivna iskustva (ako ih je bilo) podeliti sa najbližima. Zato je potrebno da se od kulturnog posetioca stvori posetilac koji je jako zadovoljan doživljenim. U tom smislu akcenat ja na proučavanju svih sfera kulturnog kontakta posetioca i ljudi i stvari na destinaciji. Ono što ostane u sećanju kulturnog turiste, navrednija je informacija na osnovu koje se donosi odluka o ponovnoj kupovini (Chen \& Rahman, 2018).

\section{KULTURNI I VERSKI TURIZAM U SRBIJI}

Kulturni turizam je najstariji oblik turizma, a putovanja inspirisana na verskoj osnovi datiraju još iz vremena antičke Grčke. Rast, koji kulturni turizam doživljava u doba globalizacije sveta, sagledan kroz broj ljudi koji u njemu učestvuju i kroz kroz udeo u BDP- mnogih država, ukazuje na to, da ovaj vid turizma doživljava pravi bum u drugoj deceniji 21. veka. Porast svih parametara kulturnog turizma (učešće u BDP-u, turistička potrošnja i sl.) u svetu nije ostao nezapažen, kao ni u Srbiji i poslednjih godina ovaj vid turizma i kulturni resursi Srbije poprimaju sve veći značaj za društvo (Mićunović et al., 2015).

U Srbiji je kulturni i religiozni turizam povezan sa antropogenim turističkim resursima. Antropogeni turistički resursi su takvi elementi destinacije, koji mogu da se iskoriste za potrebe turizma i nastali su od materijalne i duhovne kulture društva. Čine ih umetnička, graditeljska, naučna i tehnička dostignuća naroda, kao i karakteristična obeležja kulture (Maksin, 2013). Antropogene turističke resurse, prema Maksin (2013), delimo na etnografske, umetničke, ambijentalne, pejzažne i manifestacije i kao takvi čine osnov za razvoj kulturnog turizma. Kulturni turizam Srbije treba bazirati na istorijsko-umetničkom nasleđu stvorenom u Srbiji od perioda praistorije, pa do današnjih dana. Geografski položaj zemlje u kojoj živimo, donosio je kroz istoriju u ove krajeve razne civilizacije i u amanet su nam ostavljeni jedinstveni spomenici kulture, kao što su Lepenski vir, lokalitet iz šestog milenijuma pre nove ere, zatim lokalitet Vinča iz neolitskog doba, spomenici prisustva rimske imperije na ovim prostorima, o kojima svedoči Trajanova tabla u Đerdapskoj klisuri kao i ostaci gradova Sirmium, Singidunum, Viminacium, Romuliana itd. Razvoj kulturnog turizma u Srbiji treba zasnivati na ovim umetničkim kulturnim resursima, ali i na drugim spomenicima kulture, koje Srbija može da ponudi, kako domaćim, tako i stranim turistima. Turističku kulturnu ponudu treba bazirati i na valorizaciji etnografskih turističkih resursa. U te resurse, spadaju običaji, religiozni obredi, slave, svetkovine, tradicionalno obavljanje poljoprivrednih radova, spravljanje tradicionalnih pića i hrane (slaninijada, kobasicijada), tradicionalna narodna takmičenja kao što su kosidba na Rajcu, takmičenje fijakerista u Sefkerinu, tradicionalne igre, narodne nošnje, naivna umetnost itd (Maksin, 2013). Strategija razvoja turizma Republike Srbije za period od 2016-2025 nije usredsređena konkretno na razvoj verskog turizma, već se prema njemu odnosi kao delu kulturnog turizma (Radović \& Radović, 2017). Međutim, država u svojoj strategiji prepoznaje crkve i manastire, kao ključne delove kulturno-istorijskog nasleđa Srbije, koji bi trebalo da predstavljaju neizostavni deo turističke ponude Srbije (Knežević et al., 2017).

\section{SRPSKI SREDNJOVEKOVNI MANASTIRI}

Verski turizam u Srbiji povezan je u najvećoj meri sa srpskim manastirima, a nastajanje manastira usko je povezano sa državnim osamostaljenjem srednjovekovne srpske države Raške i uzdizanja srpske dinastije Nemanjića. U doba Stefana Nemanje dolazi do razvoja i izgradnje mnogih manastira, razvoja srpskog pisma itd. Prvi spomenici kulture, koji su nastali u doba Nemanjića, a danas pripadaju Srpskoj pravoslavnoj crkvi su crkve Sv. Nikole i Sv. Bogorodice u Kuršumliji i manastir Đurđevi Stupovi kod Novog Pazara (Maksin, 2013).

Manastiri Srpske pravoslavne crkve su najveći čuvari srpske istorije. Oni su svedoci krunisanja naših kraljeva dinastija Nemanjića, Obrenovića i Karađorđevića. Srednjovekovna kraljevska dinastija Nemanjića ostavila nam je $\mathrm{u}$ amanet desetine manastira neprocenjive vrednosti. Freske na zidovima ovih manastira pišu i danas udžbenike naše istorije (Mićunović et al., 2015). 
Danas postoje 423 aktivna srpska manastira, među kojima su 54 proglašena spomenicima kulture i po svojoj brojnosti su najznačajnija kategorija naše kulturne baštine. (www.srpskimanastiri.com, 2018.) Na UNESCO listi svetske kulturne baštine nalaze se manastiri: Stari Ras sa Sopoćanima, Studenica, Visoki Dečani, Pećka Patrijaršija, Bogorodica Ljeviška i Gračanica (Podovac, 2017). Ne umanjujući značaj drugih manastira, u ovom radu će se predstaviti samo neki od manastira, koji su deo najznačajnijih spomenika kulturno istorijske baštine Srbije.

Manastir Studenica je izgrađen između 1183-1196/7. Nalazi se na 4 kilometra od magistralnog puta Beograd- Novi Pazar. Svetinja je posvećena Bogorodici. Namenjena je da bude grobno mesto Stefana Nemanje. Ikonopisana je u vizantijskom stilu i na Listi svetske kulturne baštine nalazi se od 1986. godine. Najpoznatija freska manastira je ogroman prikaz raspeća Hrista iz 1209 godine. U sklopu manastira nalazi se muzej u kome se čuvaju mnogi vredni eksponati, među kojima je naročito interesantan zlatni prsten kralja Stefana Prvovenčanog. Po Maksin, (2013) saobraćajna infrastruktura Srbije ne pruža dobru dostupnost ovog manastira turistima, ali sa druge strane planiranom izgradnjom auto puta Beograd- Južni Jadran, manastir bi dobio mnogo na pristupačnosti. Stari studenički put takođe zahteva ozbiljnu rekonstrukciju. Po Maksin, (2013) manastiri su komplementarni turistički resursi i kao takav, manastir Studenica, zajedno sa srednjovekovnim utvrđenjem Maglić, manastirom Đurđevi Stupovi, manastirom Gradac, kompleksom rezidencijalnih lokaliteta iz Nemanjićkog doba i Starog Rasa, kao i manastira Sopoćani, moguće je stvoriti zasebnu turističku ponudu Ibarske zone srednjovekovnog kulturnog nasleđa. (TOS, 2018.)

Manastir Žiča se nalazi u srcu Šumadije, nadomak Kraljeva i Mataruške Banje. Podigao ga je Stefan Nemanjić u prvoj polovini 13. veka. U tom manastiru Stefan je krunisan za prvog srpskog kralja. Legenda kaže da će se posle Stefana Prvovenčanog u manastiru Žiča krunisati još šest kraljeva i za svakoga od tih kraljeva će biti otvorena, a zatim zazidana po jedna vrata. Otuda po legendi za Žiču kažu da je „sedmovrata Žiča“ Godine 1979 proglašen je za spomenik kulture od izuzetnog značaja. (www.manastiriusrbiji)

Manastir Mileševa sagrađen je između 1218 i 1228, a osnovao ga je kralj Vladislav, sin kralja Stefana Prvovenčanog. Vekovno očuvano slikarstvo, kojim su ikonopisani zidovi ove svetinje, od neprocenjive su vrednosti. Najpoznatija je freska Belog anđela, za koju kažu da ima podjednako misteriozan pogled i osmeh kao Mona Liza (gledajući iz bilo kog ugla oči Belog anđela gledaju posetioca direktno u oči). Freska „Beli anđeo“ je jedan od najlepših radova umetnosti srednjeg veka uopšte. Slike koje su poslate u svemir eventualnim razumnim bićima su slike čovekovog osvajanja Meseca, Kineskog zida i upravo freska „Belog anđela“ iz Mileševe. Vrednost potvrđuje i prvi satelitski snimak između Evrope i Severne Amerike, koji je takođe sadržao sliku „Belog anđela“. Freska je poznata i po tome što je izabrana kao jedan od najznačajnijih komada umetnosti Starog kontinenta okarakterisana u isto vreme kao simbol mira i pošiljalac poruke vere, ljubavi i nade. Manastir je kroz istoriju postao poznat i po tome što je Kralj Vladislav, 1236. godine, u Mileševu preneo telo Svetog Save iz Bugarske, gde je prvobitno bio sahranjen, a 1377. godine u Mileševi se bosanski kralj Tvrtko proglasio za kralja Srbije. (www.manastiriusrbiji)

Manastir Manasija je zadužbina despota Stefana (u narodu poznat i kao Stefan Visoki). Despot Stefan bio je srpski srednjovekovni vladar postnemanjićkog doba. Manastir je gradio između 1407. i 1418 godine kao svoju zadužbinu. Bio je veliki vladar, iskusan diplomata, a u isto vreme i veliki prosvetitelj i pokrovitelj umetnosti i kulture. Za vreme svog života i vladavine važio je za jednog od najpoštovanijih članova dvadesetčetvorice vitezova Zmajevog reda. Kao književnik i umetnik ostavio je iza sebe veći broj književnih radova, od kojih je najpoznatija poetska poruka „Slovo ljubve“ iz 1409. Za vreme vladavine despota Sefana, manastir Manasija bio je kulturni centar cele despotovine, a i kasnije je to ostao tokom celog 15. i 16. veka. Živopis manastira Manasije je jedan od najvećih dometa srednjovekovnog slikarstva celoga sveta. Veliki despot, koji je manastir postavio u centar srpske srednjovekovne kulture toga doba, upokojio se 1427 godine i sahranjen je u manastiru gde se i danas nalaze njegove mošti. (www.manastiriusrbiji)

\section{SRPSKA PRAVOSLAVNA CRKVA I TURISTI}

Verski turizam je vrlo kompleksan vid turizma. (Ivanović \& Rot, 2014) Jedan od njegovih zadataka je pomirenje interesa turističkog i kulturnog sektora, sa jedne strane i verskih zajednica i hodočasnika sa druge (Mićunović et al., 2015). Mićunović i ostali, (2015) pozivajući se na Čomića i Kalmića, (2006) a kako bi bolje 
objasnili razliku između turiste i hodočasnika, daju sledeći opis ove dve kategorije. I jedni i drugi su putnici i to je ono što im je zajedničko, ali hodočasnik je osoba koja svetom mestu prilazi sa puno ljubavi i vere, dok je turista neko, ko svetom mestu prilazi više iz radoznalosti i neretko zbog par novih fotografija.

Srpski pravoslavni manastiri u svom posedu imaju hram i druge građevine. Mogu biti muški i ženski manastiri (nikako mešoviti) i opredeljeni su ka molitvi i radu. Monasi u manastiru žive po određenim pravilima, koje turisti svakako mogu poremetiti. Sa druge strane, svako ko je posetio pravoslavne manastire u Srbiji, nije osetio odbojnost tih manastira prema turistima. Iako crkva posete svojim manastirima na tretira kao turističke, ona u isto vreme ne pokazuje odbojnost prema turističkim posetama manastirima. Stav crkve je takav, da niko od nas ne zna zašto je Gospod nekoga uputio prema svetinji koju posećuje (Nikolić, 2010). Manastiri su i zbog takvih okolnosti uglavnom dobro pripremljeni za doček turista. To se pre svega ogleda u velikom izboru suvenira za turiste i hodočasnike. Manastiri u Srbiji nisu turistički orijentisani, ali u svojoj ponudi često imaju i proizvode domaće radinosti, kao što su med, vino i sl. Na ovaj način, skoro svi manastiri dolaze do izvesnih finansijskih sredstava korisnih za popunu manastirskih budžeta.

Međutim, ponuda Srpske pravoslavne crkve u pogledu pokloničkih putovanja (termin koji je za crkvu prihvatljiv za putovanja koja se organizuju u svrhu posete pravoslavnim svetinjama) je jako skromna. Konkretno, ako se napravi paralela u odnosu na ponudu npr. Ruske pravoslavne crkve, razlika je velika (na sajtu Srpske pravoslavne crkve ili njene pokloničke agencije, ponuda za poklonička putovanja je znatno skromnija u odnosu na zvanični sajt Ruske pravoslavne crkve, koji u svojoj ponudi ima veliki broj različitih pokloničkih tura) (Nikolić, 2010). Nikolić navodi da je jedan od prvih koraka u pravcu predstavljanja naših manastira svetu bio 40. sajam turizma u Novom Sadu 2007 god., kada je mr. Radivoj Mračević, po prvi put, predstavio potencijale za razvoj verskog turizma. Na sajmu je ocenjeno da Srbija ima realne šanse da postane lider u regionu u pogledu verskog i pokloničkog turizma. Od tada do danas se nije mnogo uradilo. Jedan od problema je nedostatak kvalifikovanih ljudi za ovaj vid turizma. Nikolić, citirajući Patrijarha Moskovskog i cele Rusije, Kirila, još jednom ukazuje na značaj kvalifikovanih, stručnih i religioznih kadrova u organizaciji pokloničkih putovanja. (Nikolić, 2010)

\section{ZAKLJUČNA RAZMATRANJA}

Kultura i turizam u budućnosti moraju podići nivo kompatibilnosti i zajedničkog ostvarivanja ciljeva razvoja turizma. To podrazumeva izgradnju turističke ponude, koja će biti zasnovana na kulturnim i umetničkim potencijalima i oslonjena na edukaciju kadrova. Takav kadar, pored osnovnih znanja iz oblasti kao što su ekonomija, menadžment, marketing, moraće da poseduje i specijalistička znanja iz oblasti turizma i kulture (Milošević, 2013).

Broj turista svake godine je sve veći potvrđuju predviđanja UNWTO. Kulturni turizam u svetu takođe doživljava bum. Sa stanovništa pružalaca turističkih usluga i hodočasnici su turisti, jer na isti način konzumiraju turističku uslugu, s tim što deo svog boravka koriste u realizaciji verskih potreba. Turistička kretanja usmerena prema verskim objektima donose i značajne finansijske efekte. Veliki je broj turista, koji posećuju verske objekte na destinacijama kao što su Sveta Zemlja, Sveta Gora, Meka, Vatikan i troše značajna sredstva u te svrhe (Mićunović et al., 2015).

Svetski i domaći turisti su „gladni“ turističke ponude koja će im posle putovanja ostati u sećanju. Srbija, u takvim okolnostima, ima uslove da pruži jedinstvenu i veoma primamljivu kulturnu turističku ponudu. U smislu kulturnog turizma, to su svakako brojna arheološka nalazišta, manifestacije, festivali, ali i srednjovekovni manastiri, koji su biseri srpske duhovnosti i kulturno-istorijskog nasleđa. Finansijski aspekt i dobit ostvaren kroz turistička kretanja je jako bitan u turizmu, ali sigurno da na te aspekte ne treba gledati kratkoročno. U tom smislu, nama su potrebni edukovani turistički radnici, koji dobro poznaju uslove turizma u Srbiji sa jedne, i odnosi i zakoni koji se vekovima poštuju u manastirima Srpske pravoslavne crkve, sa druge strane. Turistički vodiči, koji predvode verske ture, treba da poseduju šira znanja od vodiča koji predvode turističke ture.

Neophodno je naglasiti, da verski turizam, sagledavajući sve aspekte, može doneti i određene nepoželjne pojave u društvu. Jedan od takvih negativnih primera su Meteori u Grčkoj. Valorizacija ovih manastira u turističke svrhe dovela je do toga, da danas u njima više nema monaha, niti se vrše verske službe. Meteori su 
kao turistička atrakcija doživeli vrhunac, ali su sa druge strane, u verskom smislu, izgubili ono što su vekovima održavali, tj. monaški život i liturgiju. Turista je dobio izuzetno mesto za fotografisanje, a u isto vreme svet je sa duhovne strane izgubio vekovno duhovno nasleđe. Ovi biseri pravoslavnog hrišćanstva sada su muzeji (Mićunović et al., 2015). Meteori, nekada vredni resurs verskog turizma, postali su kulturni turistički resurs

Između turističkog kulturnog projekta Srbije i Srpske pravoslavne crkve mogu se naći kompromisna rešenja, koja bi dovela do ekspanzije ovog oblika turizma, uz zadržavanje običaja i ostvarivanje finansijskih efekata i za manastire i za razvoj verskog odnosno kulturnog turizma u Srbiji. Izdvojenost manastira od spoljašnjeg sveta je preduslov njihovog opstanka, ali i ograničavajući faktor korišćenja ovih kulturno-istorijskih objekata $\mathrm{u}$ turističke svrhe. Povećanje broja visoko obrazovanih monaha u Srpskim manastirima ide na ruku razvoju verskog turizma uz očuvanje liturgije u tim ustanovama (Spik, 2016). Potencijali Srbije za razvoj verskog turizma, koju su do sada predstavljeni i po kojima je verski turizam trebao da postane nacionalni projekat, ipak se još uvek nisu obistinili. U narednom periodu, zajedničkim naporom crkve, države i privatnog sektora treba valorizovati postojeće potencijale i pretvoriti ih u komparativne prednosti, a vreme će pokazati da li će Srpski manastiri uspeti da očuvaju sve duhovne vrednosti koje danas imaju ili će poput bezbroj manastira u Grčkoj i na Bliskom Istoku postati samo muzeji umetnosti (Spik, 2016).

\section{LITERATURA}

Chen, H., \& Rahman, I. (2018). Cultural tourism: An analysis of engagement, cultural contact, memorable tourism expierence and destination loyalty. Tourism Management Perspectives, 153-163. DOI:10.1016/j. tmp.2017.10.006

Čomić, Đ., \& Kalmić, L. (2006). Savremene tendencije u turizmu, hotelijerstvu i gastronomiji 2006., (p.11). Novi Sad: Prirodno matematički fakultet, Departman za geografiju, turizam i ugostiteljstvo.

Ivanović, S., \& Rot, E. (2014). Razvoj preduzetništva u destinaciji verskog turizma. Turističko poslovanje, 14, 61-69. DOI:10.5937/TurPos1414061I

Knežević, M., Borovčanin, D., Džamić, V., \& Radojević, T. (2017). Značaj društvenih mreža u promociji srpskih manastira. Sitcon, 140-145. DOI:10.15308/Sitcon-2017-140-147

Maksin, M. (2013). Turizam i prostor. Beograd: Univerzitet Singidunum.

Manastiri u Srbiji (2018). Preuzeto sa http://manastiriusrbiji.com

Mićunović, G., Novaković, N., \& Stefanović, G. (2015). Verski turizam i mogući negativni efekti u odnosu na manastire. BizInfo, 43-52. DOI:10.5937/BIZINFO1501043M

Milošević, S. (2013). Činioci razvoja kulturnog trizma- studija slučaja Bar, Crna Gora. Poslovna ekonomija, 259-280. DOI:338.48-6:7/8

Nikolić, V. (2010). Verski turizam i Srpska pravoslavna crkva. (V. M. Nikolić, Ur.) Doktorska disertacija, 8.

Pivac, T. (2018). Kulturni turizam. Preuzeto sa http://www.dgt.uns.ac.rs/download/kultreligindturizam240516. pdf

Podovac, M. (2017). Uloga i značaj manastira u pozicioniranju Srbije kao destinacije verskog turizma. Verski turizam i savremeno turističko tržište, 183-188. DOI:10.15308/Sitcon-2017-183-188

Podovac, M., Jovanović-Tončev, M., \& Milićević S. (2016). Istraživanje stavova ispitanika o potencijalima Vrnjačke banje za njen razvoj kao destinacija kulturnog turizma. Poslovna ekonomija, 265-283. DOI: 10.5937/poseko 10-12296

Popesku, J. (2018). Savremena kretanja u turizmu.

Radović, N., Stevanić, B., Stojanović, N., \& Radović, M. (2017). Digitalni mediji u funkciji unapređenja kulturnog turizma. Proceedings of the International Scientific Conference (str. 395-399). Beograd: Univerzitet Singidunum. DOI:10.15308/Sinteza-2017-395-399

Radović, N., \& Radović, M. (2017). Verski turizam u funkciji razvoja turističkih destinacija Srbije. 51-54. Beograd: Univerzitet Singidunum. DOI:10.15308/Sitcon-2017-51-54

Richards, G. (2018). Cultural tourism: A review of recent research and trends. Journal of Hospitality and Tourism Management, 36, 12-21. DOI:10.1016/j.jhtm.2018.03.005

Spik, G. (2016). Sveta Gora - obnova u Raju. Beograd: Zadužbina Svetog manastira Hilandara.

Todorović, B., \& Maksimović-Rubežanović, L. (2014). Mesto i značaj planinskog turizma u savremenim turističkim kretanjima. Ekonomska škola Užice: Ekonomika, 179-188. 
TOS. (2018). Manastiri. Preuzeto sa www.serbia.travel: http://www.serbia.travel/kultura/manastiri.394.html

UNWTO. (2017). 22nd UNWTO General Assembly in China: a week of important achievements Preuzeto sa World Tourism Organization UNWTO: http://media.unwto.org/press-release/2017-09-18/22nd-unwtogeneral-assembly-china-week-important-achievements

\title{
SERBIAN MEDIEVAL MONASTERIES AS A LINK BETWEEN RELIGIOUS AND CULTURAL TOURISM
}

\begin{abstract}
:
There are many elements that link culture and tourism. Culture is present constantly and everywhere, and tourism "seeks" culture to meet the needs of travellers. Cultural tourism is becoming the fastest growing segment of tourism industry. The countries that hold on to the preservation of cultural heritage generate the highest income from the visitors who are determined to get to know that heritage. Serbia has a lot of cultural and historical monuments and among them a significant number of medieval monasteries. The subject of this paper is potential valorization of Orthodox shrines, as a part of cultural heritage, for the purpose of tourism development. The heritage, which the Nemanjic dynasty and their successors have left us to protect and cherish, is the basis of religious tourism in Serbia and an invaluable legacy for the development of future tourist movements within this type of tourism.

Keywords:

cultural tourism, Orthodox church, cultural and historical monuments, religious tourism, Serbian monasteries
\end{abstract}

